\title{
Research about New Predictive-Maintenance Methodology using VBA for Marine Engineering Applications
}

\author{
José A. Orosa, Angel M. Costa and Rafael Santos \\ University of A Coruña \\ Spain
}

\section{Introduction}

Currently, one of the most important activities that helps marine engineers to maintain the quality of any service is statistical process control (SPC). Statistical process control is the applied science that helps to collect, organise and interpret the wide variety of information available for engineering applications (harris et al., 1999; Kumar et al., 2008).

SPC can help to understand and reduce the variation in any business process, which thus leads to less expenditure of time and money on rework and waste.

In the first place, control charts show how consistently a process performs and whether or not we should attempt to adjust it. Second, it compares the process performance to customer requirements, providing a process-capability index that functions as an ongoing, accurate indicator for improvement of quality. Finally, the resulting process-capability index facilitates a quick evaluation of the results of quality initiatives designed to improve process consistency.

Because it involves complex mathematics, computers are ideally suited to develop the SPC charts. They easily collect, organise and store information and present results in easy-tounderstand graphs, called the control charts. Computers accept information typed in manually, read from scanners, manufacturing machines or details imported from other computer databases. Furthermore, as concluded in recent research works (Vosniakos and Wang, 1997; Lee et al., 2006), a computer collecting information in real time can detect very subtle changes in a process and can even warn in time to prevent process errors before they occur.

The process model proposed in those studies included the manufacturing process, responsible for generating the product, and a measuring process, responsible for generating information about the quality.

The process evaluation leads to intelligent decision-making for quality improvement. Therefore, recent research works (Louit et al., 2009; Kumar et al., 2008) have proposed a practical procedure to discriminate between the common renewal approach towards the time-to-failure model and the use of a non-stationary model.

Currently, to automate quality-information generation, there is a certain tendency to apply private software resources furnishing quality-control charts (Statgraphics, 2009), which can solve typical engineering problems. Nevertheless, when a marine engineer tries 
to solve his particular working problems at the ship or in a power station, he cannot depend on licenses and private software-related problems that can stop his activity. Consequently, engineers must apply programming languages to develop their own applications in accordance with the particular conditions of each engine room (Cebi et al., 2009; Deris et al., 1999).

Therefore, programming languages, such as FORTRAN, Pascal and C, are not appropriate for marine engineers who must work on-site with limited resources, in contrast to the work spot of a general engineer.

As a result of previous research works and meetings with experienced marine engineers and companies, the researchers of the Department of Energy and Marine Propulsion have concluded that the programming software must be user-friendly and must not be too heavy for the computers of the power station.

Furthermore, it must be borne in mind that a marine engineer hardly ever stays in the same ship or power station; accordingly, he must be ready to start his work from scratch within a limited period of time.

From previous experiences in thermodynamic studies (Orosa, 2009), researchers have analysed the principal computing software resources, such as C, Matlab, Mathematica, Engineering Equation Solver or EES, Pascal, FORTRAN and Visual Basic. From their research, they conclude that Visual Basic for applications (VBA) is the best solution for these typical engineering problems.

Microsoft (MS) VBA is a very simple language to converse with Excel, a user- friendly programming language that can be easily used by engineers who are interested in and ready to spend some time in a very rewarding and enabling learning process. People who use applications that host VBA can automate and extend the application functions, thereby shortening the development cycle of customising engineering solutions (VBA, 2009; Verma, 2003; Verhoefa et al., 2008).

The only problem related with this language is that sufficient information is not available about VBA. Consequenly, researchers of the Department of Energy and Marine Propulsion, in collaboration with the Department of Informatics, began a self-learning process involving VBA to define a new methodology for marine engineers, which allows them reduce the time elapsed when they carry out maintenance studies at work.

In particular, this chapter presents a deeper study to generate a software resource to generate a control chart of attributes and, thereby, derive a research tool for a faster qualitycontrol study, based on the results obtained and not by the calculation process.

As explained, VBA has been selected because of its macro programming system that can be implemented with MS Excel (Wu and Liua, 2008).

\section{Objectives}

The fixed objective of this study was to automate the control chart of attributes, combining the feasibility of working with MS Excel with the user-friendly data introduction of Visual Basic, to determine the real feasibility of VBA as a working tool with reference to other private softwares.

Finally, this software has been tested under real on-board situations, such as detection of failures related to exhaust gas-temperature sampling in the main engine. 


\section{Materials}

\subsection{Programming languages}

The programming language selected was VBA of MS Office Excel 2003. Microsoft owns the VBA, whose code is compiled (Microsoft, 2010, Excel, 2010; Jelen and Syrstad, 2008 and Roman, 2002) in an intermediate language called the P-code (2010); the latter code is stored by the hosting applications (Access, Excel, Word) as a separate stream in structured storage files independent from the document streams.

The intermediate code is then executed by a virtual machine. Therefore, the obtained software resource can only be operative in a Windows-98 or above Operating System. Calculus operations and graphics are carried out in MS Excel, with a report in MS Word. Accordingly, MS Excel and MS Word must be of version 2000 or above.

\subsection{Software characteristics}

In a typical software application, the user specifies a target mean and the desired average run length before a deviation of that magnitude is detected. In real applications, after some working hours, control limits must be obtained from the data sampled and be compared with design conditions.

With the help of the Department of Informatics, the Department of Energy and Marine Propulsion began to solve typical problems and send the generated code to the corresponding module of MS Excel file. Therefore, the software designed must develop a control chart that will detect deviations of a specified magnitude within an acceptable time.

\section{Methods}

As explained before, in the present study, the exhaust-gas temperature in the engine will be analysed using control charts and related with daily events. To do it, control-chart selection and sampling of data were applied.

\subsection{Control charts of attributes}

As explained above, the control chart is one of the most important and commonly used among the Statistical Quality Control methods for monitoring process stability and variability. It is a graphical display of a process parameter plotted against time, with a centre line and two control limits (Jennings and Drake, 1997).

Attribute charts are a set of control charts specifically designed for data on attributes. Attribute data are also known as "count" data. Typically, the number of times a specific condition is observed is counted (usually something not preferred, such as an error) in a specific sample from the process.

This is different from measurement data in terms of its resolution. As a consequence of this, attribute data have less resolution because only if some error occurs is it counted, in contrast to obtaining a measurement to find the enormity of the condition.

For example, attribute data for a maintenance-care process might include the number of tasks of maintenance in a pump, whereas variable data for the same process might be the measurement of the pressure decrease in the same pump. Thus, attribute data generally provide us less information than what measurement data would for the same process. Thus, for attribute data, prediction is not possible if the process tends towards an undesirable state, because it is already in this condition. 
To select an adequate attributable control chart, each difference must be considered.

The Np-Chart monitors the number of times a condition occurs, relative to a constant sample size, when each sample can either have this condition or not.

The p-Chart monitors the percent of samples having the condition, relative to either a fixed or varying sample size, when each sample can either have this condition or not. The c-Chart monitors the number of times a condition occurs, relative to a constant sample size. In this case, a specific sample can have more than one instance of the condition, in which case, the total number of times it occurs in the sample is counted.

The $\mathrm{u}$-Chart monitors the percent of samples having the condition, relative to either a fixed or varying sample size. In this case, a specific sample can have more than one instance of the condition, in which case counting of all the times it occurs in the sample is carried out.

\section{$4.2 \mathrm{p}$-Chart calculations}

In a case study, the exhaust-gas temperature sample failure in the main engine is sampled and, consequently, the p-charts were selected. In this type of charts, the calculation of the average of all samples and the upper and lower control limits are shown in Equations 1, 2 and 3 .

$$
\begin{gathered}
\bar{p}=\frac{\sum p}{k} \\
\operatorname{CLL} p=\bar{p}+3 \cdot \sqrt{\frac{\bar{p} \cdot(1-\bar{p})}{\bar{n}}} \\
\operatorname{LCL} p=\bar{p}-3 \cdot \sqrt{\frac{\bar{p} \cdot(1-\bar{p})}{\bar{n}}}
\end{gathered}
$$

When the sample sizes are not constant, the average sample size, $\bar{n}$, should be used for $\mathrm{n}$ in the control-limit calculations, as shown in Equation 4.

$$
\bar{n}=\frac{\sum n}{k}=\frac{N}{k}
$$

Where

$\mathrm{n}=$ the sample size, the number of individuals in a sample

$\mathrm{k}=$ the number of samples

$\mathrm{N}$ = number of individuals, the total number of observations

$\mathrm{N}=\mathrm{n}$ times $\mathrm{k}$ if all samples are of the same size.

$p=$ the fraction of "successes", which may be defective items, expressed as a

decimal

$1-p=q=$ the fraction of "failures", which may be the qc-pass items.

$\mathrm{p}+\mathrm{q}=1$; hence, $\mathrm{q}=1-\mathrm{p}$.

\subsection{Software design}

To design the software, the methodology used for developing a control chart must be analysed. 
In this section, the steps that must be considered to properly develop the programme are listed:

The user must:

1. Select the characteristics of quality.

2. Determine the size of the subset if it is going to be constant.

3. Compile the data into groups.

Once the type of control chart is selected, it must be considered that, although it is possible to plot individual samples, the control chart will be distorted if they are not normally distributed and thus will not give a clear picture of any process changes.

To avoid this distortion, a sample size of four to six is adequate to detect moderate-to-large shifts in a parameter and 15-25 samples to detect small shifts. In this case study, groups of 150 samples of temperature have been selected.

The software must:

4. Permit the insertion of the data for each group.

This will automatically calculate the control limits. These limits, together with the average $\mathrm{p}$ value of all groups, will be reflected in the graph.

5. Permit the discarding of data.

It should be remembered that only those values, which are attributable subgroups identified through the day book and can be corrected, are discarded.

On the contrary, those groups whose causes are not attributable are retained as part of the data.

Moreover, items that are out of control below the lower control limit are not discarded, because these represent exceptionally good quality. If the point in the out-of-control side is due to a lower error of inspection, it must be discarded.

After eliminating the group caused by attributable reasons, the software must automatically re-calculate and re-present the control limits. Once the p-graph is under control, a comparative study can be carried out with reference to the product specifications of the previous studies. For this, the control limits must be found within the area bounded by the specifications.

These specifications are the typical values of the product to be analysed, which are introduced into the programme the first time that data are inserted into the area above the control limits.

6. The software must let a clear output of information.

In summary, it can be concluded from these steps that the software must plot the sample data, define the control limits, delete the data related to attributable causes, and recalculate the limits of the process towards a controllable situation.

\section{Results}

\subsection{Software}

The methodology begins with the automation of the calculus of Equations 1, 2 and 3 in MS Excel, as shown in Figure 1.

In the figure, it can be observed that the engineers must automate the selection of constants in MS Excel in accordance with the problem data.

Subsequently, the main screen of the software has been developed with VBA and is represented in Figure 2. 


\begin{tabular}{|c|c|c|c|c|c|c|c|c|c|}
\hline \multicolumn{10}{|c|}{$\$$ Microsoft Excel - P } \\
\hline \multirow{3}{*}{\multicolumn{10}{|c|}{ 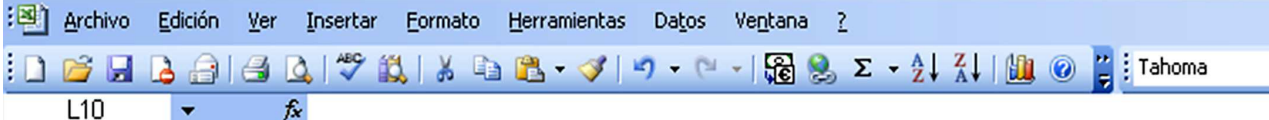 }} \\
\hline & & & & & & & & & \\
\hline & & & & & & & & & \\
\hline & $B$ & $\mathrm{C}$ & D & $E$ & $\mathrm{~F}$ & G & $\mathrm{H}$ & 1 & $\mathrm{~J}$ \\
\hline \multicolumn{9}{|l|}{$\begin{array}{l}1 \\
2 \\
\end{array}$} & \\
\hline \multirow[t]{2}{*}{4} & & GRUPO & $\mathbf{n}$ & $\mathrm{np}$ & p & LCS & LCI & DIARIO & \\
\hline & & 1 & & & & & & & \\
\hline \multirow[t]{2}{*}{6} & & 2 & & & & & & & \\
\hline & & 3 & & & & & & & \\
\hline \multirow{2}{*}{\multicolumn{2}{|c|}{ 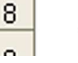 }} & 4 & & & & & & & \\
\hline & & & & & & & & & \\
\hline
\end{tabular}

Fig. 1. Calculus automation in MS Excel

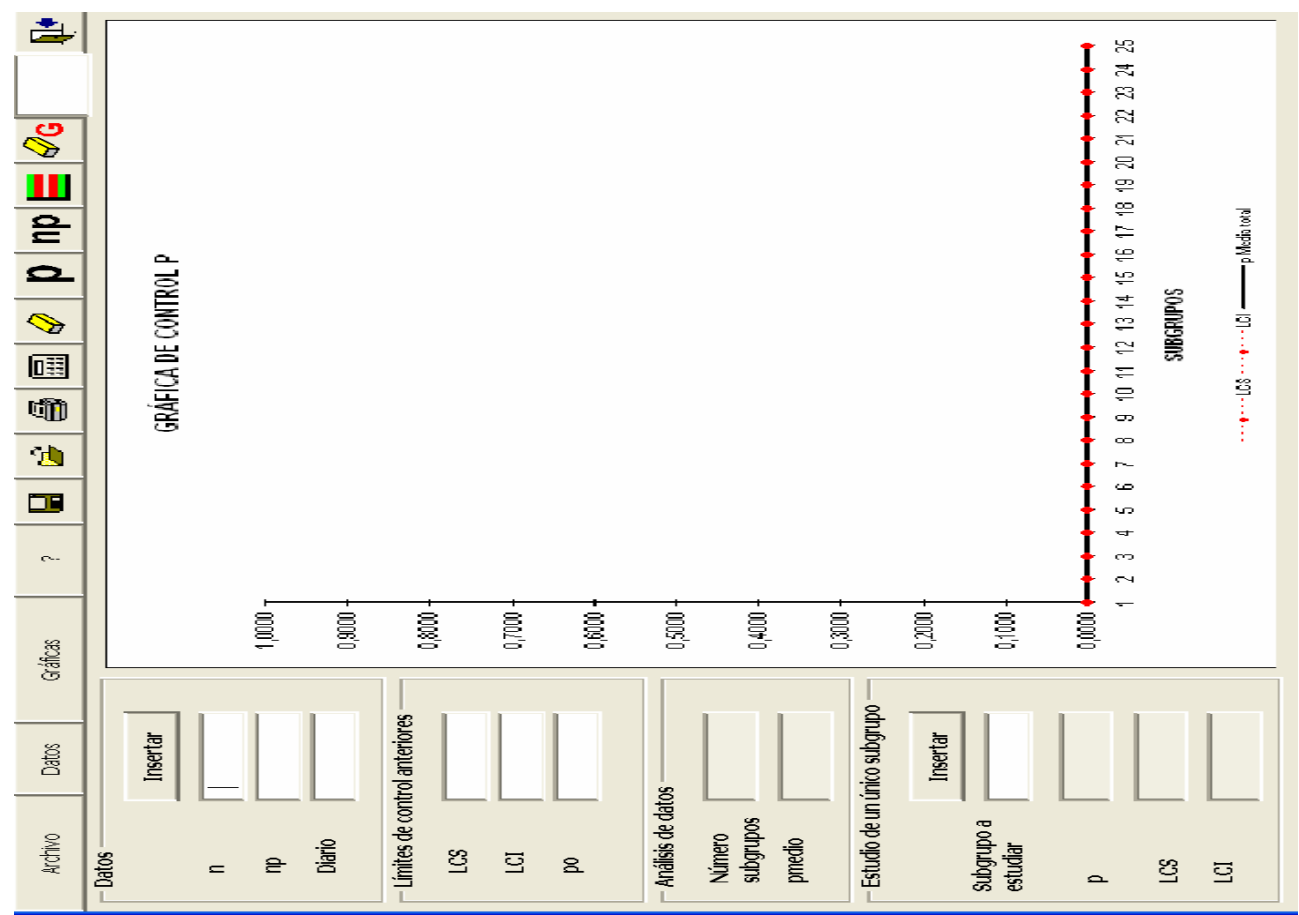

Fig. 2. Control Chart of the attributes $P$

\subsection{Control-chart test}

A test of the software developed was carried out with the sample data of the number of errors sampled in the exhaust-gas temperature of the main engine (np), figure 3. 
Most ofen, they were instantaneous sampling failures and, in other cases, real sensor failure. It was proposed to characterise the process with the aim of differentiating between instantaneous and real sampling failures. For this purpose, the data was sampled in groups of a constant value of 150 samples, as shown in Table 1, and compared with other software resources, such as Statgraphics.

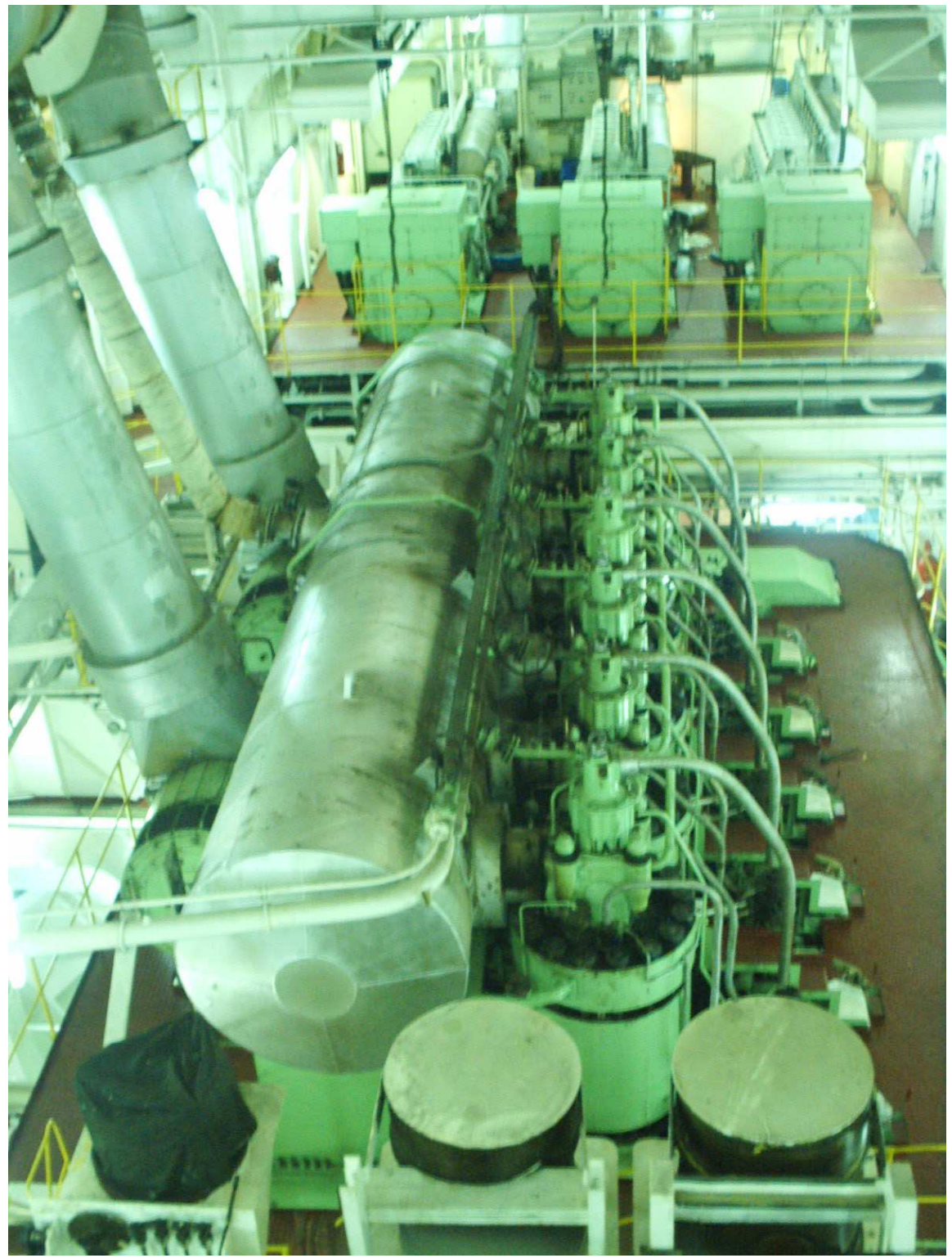

Fig. 3. Main engine 


\begin{tabular}{|c|c|c|}
\hline subgroup & $\mathrm{n}$ & $\mathrm{np}$ \\
\hline 1 & 150 & 6 \\
\hline 2 & 150 & 1 \\
\hline 3 & 150 & 4 \\
\hline 4 & 150 & 2 \\
\hline 5 & 150 & 0 \\
\hline 6 & 150 & 3 \\
\hline 7 & 150 & 3 \\
\hline 8 & 150 & 1 \\
\hline 9 & 150 & 4 \\
\hline 10 & 150 & 5 \\
\hline 11 & 150 & 1 \\
\hline 12 & 150 & 5 \\
\hline 13 & 150 & 4 \\
\hline 14 & 150 & 1 \\
\hline 15 & 150 & 0 \\
\hline 16 & 150 & 2 \\
\hline 17 & 150 & 3 \\
\hline 18 & 150 & 4 \\
\hline 19 & 150 & 8 \\
\hline 20 & 150 & 1 \\
\hline 21 & 150 & 2 \\
\hline 22 & 150 & 3 \\
\hline 23 & 150 & 0 \\
\hline 24 & 150 & 1 \\
\hline 25 & 150 & 1 \\
\hline
\end{tabular}

Table 1. Number of sampling errors detected in each group of 150 samples 


\subsection{Test results}

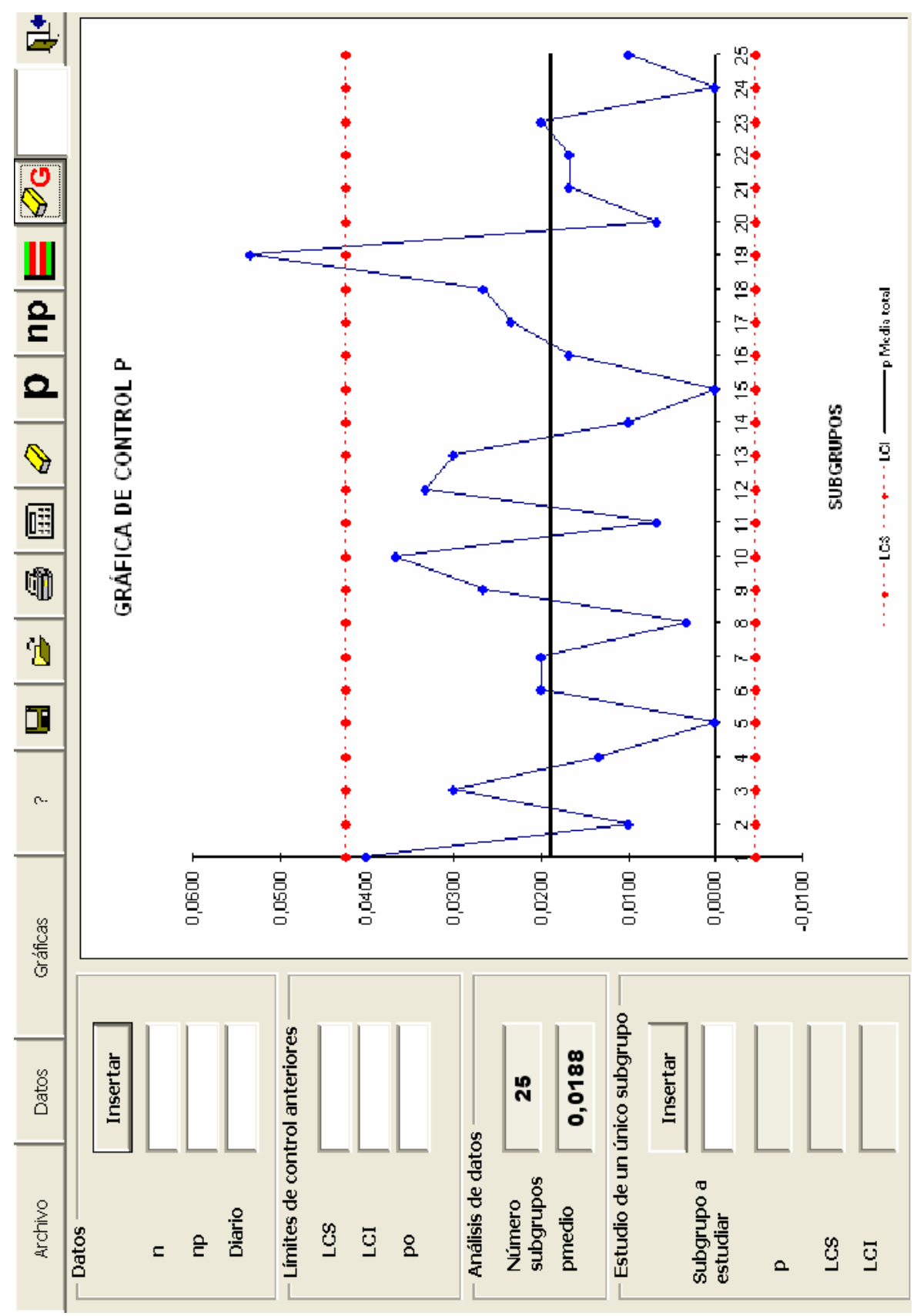

Fig. 4. Graphic units do not comply 


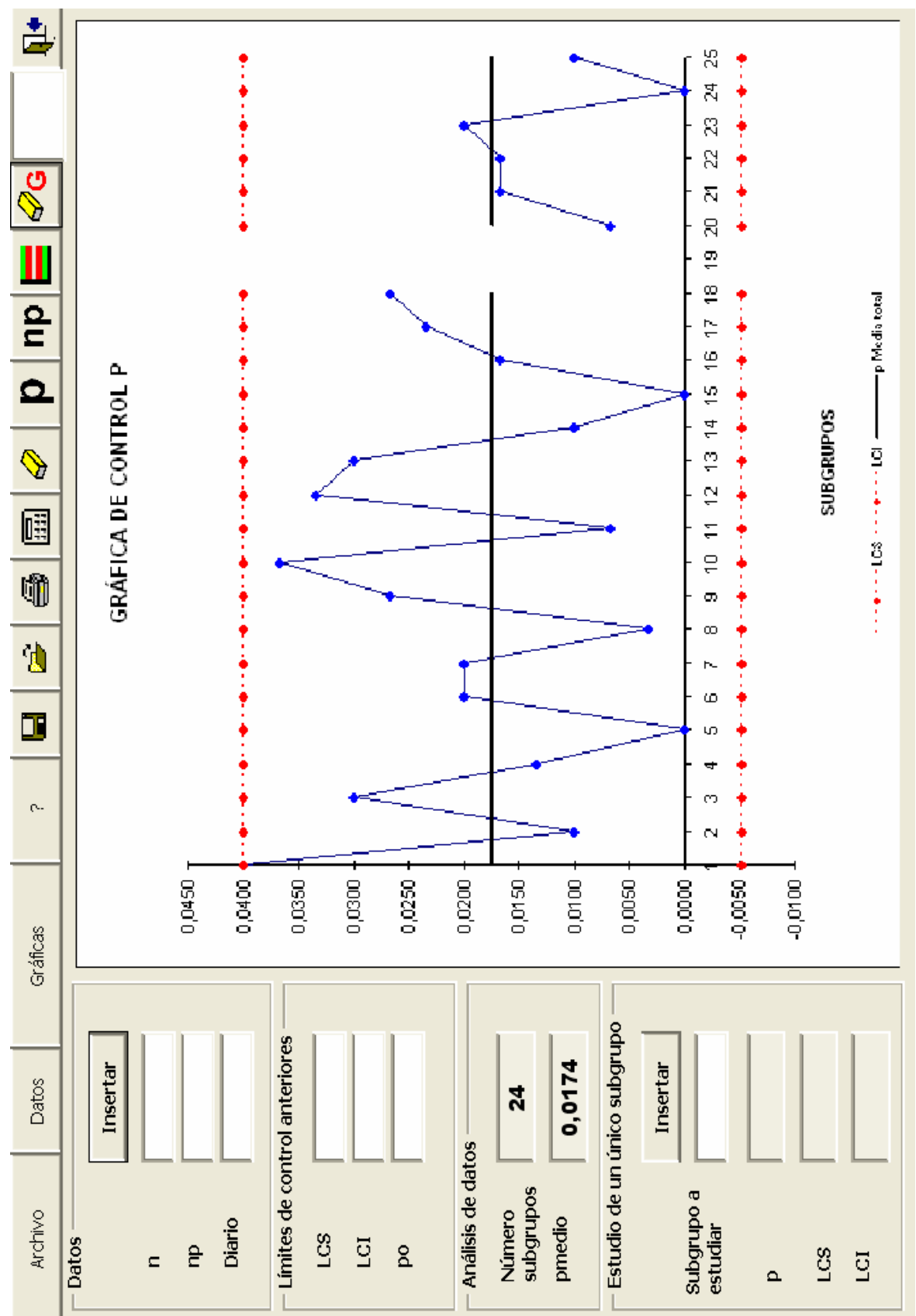

Fig. 5. Control Chart limits 


\section{Discussion}

Statistical Process Control is the applied science that helps to collect, organise and interpret the wide variety of information available for engineering applications. This manuscript describes a study about development of the optimal methodology to develop a qualitycontrol analysis of attributes.

As explained above, after the selection of the characteristics of quality and the size of groups, the calculus was automated to show the general solution of the problem of Figure 1. This screen will help persons who do not want to waste too much time to solve the mathematical solutions of the problem and want to improve the quality of the process.

As observed from Figure 2, when the programme is started, it displays the main menu of operation.

This screen shows the menus: file, data, graphs and help such as in other Visual Basic software. The options to save, open, print, delete, insert data and delete group are also inserted. In this screen, the number of groups, diary comments and specifications limits are added. Finally, the output data are shown as mean values and limits in the bottom of the screen.

Once all the data are inserted, each chart includes the statistically determined upper and lower control limits, indicating the bounds of the expected process behaviour (Figures 4 and $5)$.

The fluctuation of the points between the control limits is due to the intrinsic variation of the process. In other words, this variation is due to "common causes" that influence the process. Any points outside the control limits can be attributed to a "special cause," implying a shift in the process. When a process is influenced by only the common causes, it is stable and can be predicted. Thus, the main role of the control chart is to identify the occurrence of special causes, so that they can be removed, resulting in a reduction of variation in the overall process.

Subsequently, the process can be further improved by either relocating the process to an optimal average level or decreasing the variation due to common causes. Once the software is developed, it is tested using real case studies, which shows a clear agreement with other software resources, such as Stat graphics.

In this case study, the exhaust-gas temperatures of the main engine were sampled in groups of 150 samples and the number of sampling errors was noted. From this data, and using the herein-developed software, it was analysed and the control limits of the exhaust gas temperature were determined.

After calculating the control limits, the chart must be interpreted by looking for out-ofcontrol points. If there are any points, their special causes must be eliminated. Conduct brainstorming sessions and experiments designed to find those process elements that contribute to sporadic changes in process location.

To use the data in hand, auto drop is turned on, which will remove the statistical bias of the out-of-control points by omitting them from the calculations of the average and control limits.

In particular, one of the 25 samples exceeded the upper limit. This value was related to an attributable reason of abnormal combustion and could be discarded, as shown in Figure 4 . From this same figure, changes in the process-control limits and mean values can be observed. These values define the real conditions of the main engine temperatures. 
Nevertheless, even when all the points on a control chart are within the control limits, a process can still display out-of-control behaviour due to systematic or random behaviour. This can be identified by the points showing a process shift, a trend or a recurring cycle, or the points forming two groups on either side of the process average.

These patterns can be identified by the Western Electric Control Rules:

1. One point lies outside $(3 \times$ standard deviation) $(\mathrm{SD})$

2. Two out of three consecutive points plotted are greater than $2 \times \mathrm{SD}$.

3. Four out of five consecutive points plotted are greater than $1 \times \mathrm{SD}$.

4. Eight consecutive points are plotted on one side of the central line.

5. An unusual or non-random pattern in the data.

In accordance with this methodology, the normalised data was processed and plotted, after deleting the attributable failure, as observed in Figure 4. The authors' effort to detect tendencies in the case study was not fruitful with reference to the ranges of SD.

It was related with a good maintenance periodicity. Because of this characteristic, this evolution must be analysed with a certain frequency to detect future failures due to wastage of elements.

To get a report of the analysis, the output information can be furnished through the data shown in the main menu by printing or generating a report in MS Word.

In particular, it is very easy to generate a report in MS Word with VBA due to the fact that it works in most of the MS resources, such as Word, Power Point and Access, among others. This report consists of three control charts and a data table showing the values obtained numerically.

Another advantage of the software is that, once developed, it permits engineers to solve a high number of control-chart problems within a few minutes and, consequently, use most of the time to understand the results and brainstorm thought the chart analysis.

Finally, it should be noted that this methodology presents a disadvantage. To obtain an adequate behaviour, the software needs an executable file that locates the files in each directory and creates the corresponding shortcuts of initialisation and uninstalls the software.

This packing has been carried out with private software due to the fact that VBA does not possess this option.

In summary we can say that results show that Visual Basic for Applications is the most adequate language that can reduce the programming time and is compatible within the available limited resources.

Furthermore, time elapsed in solving a typical maintenance study is reduced to less than fifty per cent of the time required in the classical method. In spite of this advantage, a selfexecutable file is lacking, which must be developed as a future improvement of the methodology.

\section{Conclusions}

Statistical Process Control is the applied science that helps to collect, organise and interpret the wide variety of information available for engineering applications. This manuscript describes a study about development of the optimal methodology to develop a qualitycontrol analysis of attributes. 
As shown in this report, VBA is an interesting tool to design new engineering software resources and to subsequently implement the learning methods. This new methodology for each engineering application lets students to be self-adapted to each real condition at work. Furthermore, once the software is developed, it lets students solve a high number of controlchart problems within a few minutes and spend most of the time in understanding the results through the charts study.

Nevertheless, in spite of the fact that VBA has clear advantages with reference to other typical programming languages, it has not been exploited in depth during the preceding years by professors and engineers. Consequently, this language does not have its own packing tools that generate, install and uninstall files and icons.

For the future implementation in newer MS Office versions, it will be interesting to implement these tools and evolve a definitive teaching methodology that involves less time. This methodology must be implemented along with more information, such as books and student guides (El-Khouly et al., 2000).

Finally, future research studies must be completed for quantification of the real learningtime implementation obtained with this new methodology and its advantages in accordance with the Bologna declaration.

\section{Acknowledgements}

We record our appreciation for the sponsorship extended by the University of A Coruña to this project under its IV Contract Programme (2008).

\section{References}

Cebi, S.; Celik, M.; Kahraman, C.; and Deha, I. (2009). An expert system towards solving ship auxiliary machinery troubleshooting: SHIPAMTsolver. Expert Systems with Applications. 36. pp.7219-7227.

Deris, S.; Omatu, S.;Ohta, H.; Shaharudin Kutar, Lt Cdr; Samat, P. A. (1999). Ship maintenance scheduling by genetic algorithm and constraint-based reasoning. European Journal of Operational Research. 112. pp.489-502.

Discovering Macros of Visual Basic for Applications (VBA) for Microsof Excel. Introduction to VBA. http://www.excel-vba.com/excel-vba-introduction.htm. Accessed June 2010.

El-Khouly, M. M.; Far, B. H.; Koono, Z. (2000). Expert tutoring system for teaching computer-programming languages. Expert Systems with Applications, Vol. 18, No. 1, pp. 27-32. ISSN:0957-4174.

Harris, T. J., Seppala, C. T. and Desborough, L.D. (1999). A review of performance monitoring and assessment techniques for univariate and multivariate control systems. Journal of Process Control. 9. pp. 1-17. ISNN: 0959-1524.

Jelen, B.; Syrstad, T. (2008). Visual Basic for Applicatiosn (VBA) and macros for Microsoft Office Excel 2007 (business solutions), Second edition, Indianapolis, pp. 42-52. ISBN: 0789736829.

Jennings, A.D. and Drake, P.R. (1997). Machine tool condition monitoring using statistical quality control charts. International Journal of Mach. Tools Manufact. Vol. 37, No. 9 pp.1243-1249. ISSN:0890-6955. 
Kumar Sharma, R., Kumar, D. and Kumar, P. (2008). Predicting uncertain behaviour of industrial system using FM- A practical case. Applied Soft Computing. 8. pp.96-109. ISSN:1568:4946

Lee, S. Lee, J. K. Park, B. Lee, D. Kim, S. Lee, K. (2006). Development of internet-based ship technical information management system. Ocean Engineering. 33 1814-1828. ISSN:0029:8018.

Louit, D. M., Pascual, R. and Jardine, A.K.S. (2009). A practical procedure for the selection of time to failure models based on the assessment of trends in maintenance data. Reliability Engineering \& System Safety. doi:10.1016/j.ress.2009.04.001. ISSN: 09518320.

Microsoft P-Code technology. http://msdn.microsoft.com/es-es/default.aspx. Accessed June 2010.

Microsoft Help. ACC: Visual/Access Basic Is Both a Compiler and an Interpreter. Accessed June 2010.

Orosa, J.A. (2009). Programming languages for Marine Engineers. Computer Applications In Engineering Education. DOI:10.1002/cae.20339.ISSN: 1061-3773.

Quality Control Charts.

http://www.qualityamerica.com/knowledgecente/knowctrWhen_to_Use_an_Attr ibute_Chart.htm. Accessed June 2010.

Roman, S. (2002). Writing Excel Macros with VBA. Sebastopol CA: O'Reilly, Chapter 15. ISBN: 0596003595.

Statgraphics Centurion Web page. http://www.statgraphics.com/control_charts.htm\#variables. Accessed April 2009.

Verhoefa, A.; Degrèvea, J.; Huybrechsa, B.; Van Veenb, H.; Pexb, P. and Van der Bruggena, B. (2008). Simulation of a hybrid pervaporation-distillation process. Computers $\mathcal{E}$ Chemical Engineering, Vol. 32, No. 6, Pages 1135-1146. doi:10.1016/j.compchemeng.2007.04.014. ISSN: 0098-1354.

Verma, M. P. (2003). Steam tables for pure water as an ActiveX component in Visual Basic 6.0. Geotermia, Instituto de Investigaciones Electricas. Computers \& Geosciences, Vol. 29, No 9, pp. 1155-1163. DOI:10.1016/S0098-3004(03)00136-5. ISSN: 0098-3004.

Visual Basic for Applications Frequently Asked Questions. http://msdn.microsoft.com/enus/isv/bb190540.aspx. Accessed February 2009.

Vosniakos, G \& Wang, J. (1997). A software system framework for planning and operation of quality control in discrete part manufacturing. Computer integrated Manufacturing Systems, Vol. 10, No 1. pp.9-25. ISSN:0951-5240.

Wu, C.; Liua, Y. (2008). Development and evaluation of an ergonomic software package for predicting multiple-task human performance and mental workload in humanmachine interface design and evaluation. Computers $\mathcal{E}$ Industrial Engineering, doi:10.1016/j.cie.2008.06.013. ISSN: 0360-8352. 


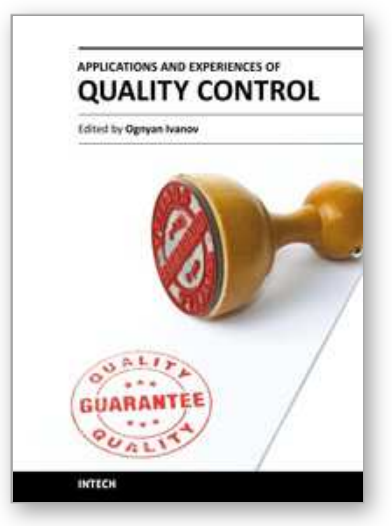

\section{Applications and Experiences of Quality Control \\ Edited by Prof. Ognyan Ivanov}

ISBN 978-953-307-236-4

Hard cover, 704 pages

Publisher InTech

Published online 26, April, 2011

Published in print edition April, 2011

The rich palette of topics set out in this book provides a sufficiently broad overview of the developments in the field of quality control. By providing detailed information on various aspects of quality control, this book can serve as a basis for starting interdisciplinary cooperation, which has increasingly become an integral part of scientific and applied research.

\section{How to reference}

In order to correctly reference this scholarly work, feel free to copy and paste the following:

José A. Orosa, Angel M. Costa and Rafael Santos (2011). Research about New Predictive-Maintenance Methodology using VBA for Marine Engineering Applications, Applications and Experiences of Quality Control, Prof. Ognyan Ivanov (Ed.), ISBN: 978-953-307-236-4, InTech, Available from:

http://www.intechopen.com/books/applications-and-experiences-of-quality-control/research-about-newpredictive-maintenance-methodology-using-vba-for-marine-engineering-applications

\section{INTECH}

open science | open minds

\author{
InTech Europe \\ University Campus STeP Ri \\ Slavka Krautzeka 83/A \\ 51000 Rijeka, Croatia \\ Phone: +385 (51) 770447 \\ Fax: +385 (51) 686166 \\ www.intechopen.com
}

\author{
InTech China \\ Unit 405, Office Block, Hotel Equatorial Shanghai \\ No.65, Yan An Road (West), Shanghai, 200040, China \\ 中国上海市延安西路65号上海国际贵都大饭店办公楼 405 单元 \\ Phone: +86-21-62489820 \\ Fax: $+86-21-62489821$
}


(C) 2011 The Author(s). Licensee IntechOpen. This chapter is distributed under the terms of the Creative Commons Attribution-NonCommercialShareAlike-3.0 License, which permits use, distribution and reproduction for non-commercial purposes, provided the original is properly cited and derivative works building on this content are distributed under the same license. 